\title{
Social media in tourism: a visual analytic approach
}

\author{
Mingming Cheng* and Deborah Edwards \\ UTS Business School, University of Technology Sydney, Sydney, Australia
}

(Received 2 December 2014; accepted 26 March 2015)

This research note seeks to examine a vast amount of tourism-related Chinese social media posts using a visual analytic approach. Visual analytics turns information overload into an opportunity. In this case, the mainstream Chinese microblog service, Sina Weibo, was selected as it generates large volumes of data, representing significant consumer insights, that are challenging to analyse by other common research methods. The most frequently reposted tourist visa news in the first eight months of 2014 were harvested and used as a case study. Findings from this study demonstrate that a visual analytic approach can offer insights into the impact of travel news on Chinese consumers. These insights include potential tourist generating regions, the life span of travel news, and tourists' attitudes towards travel policy changes. Such insights provide important implications for scholars and practitioners, such as enabling real-time decisions of DMOs' social media marketing strategies in China.

Keywords: data visualization; China; social media; visual analytics; method

\section{Introduction and literature review}

\section{Social media and Sina Weibo}

The use of social media has become a major social phenomenon and a global business trend (Hays, Page, \& Buhalis, 2013). Similarly, there has been an increase in attention on social media as a source of research data in areas such as consumer decision-making process (Hudson \& Thal, 2013), e-word of mouth (Ye, Law, Gu, \& Chen, 2011), and travel recommendations (Kurashima, Iwata, Irie, \& Fujimura, 2010). Much of this research has been undertaken in a Western context with the social media landscape in China largely unexplored. In particular, Sina Weibo, the Chinese version of Twitter is less known to Western researchers as the majority of its users are located in China and only post in Chinese language. Although Twitter is the dominant worldwide microblog service, it has been blocked and made unavailable in China since mid-2009 (Sullivan, 2012). Sina Weibo's platform and mode of user interaction are similar to Twitter, and it subsequently has become the dominant Chinese microblog service (Ramzy, 2011). According to Xinhua News (2013) by the end of 2012, Sina Weibo had more than 500 million users and was growing at a rate of nearly 14 million registered users per month. Consequently, as a data source it contains valuable consumer insights.

Different from Twitter users, Chinese users are more active in reposting and the reposting process contains valuable information that further propogates information with flow on 
effects of a particular posting (Ren, Zhang, Wang, Li, \& Yuan, 2014). Moreover, Chinese consumers are personally connected to Sina Weibo and trust social media content more than their Western counterparts (Nelson, 2013). One area to which Sina Weibo users are particularly responsive is tourist visa news (Mairin, 2014). Responses to such postings, that number in the thousands, can reflect significant consumer opinions that provide market intelligence for destination managers and tourism stakeholders with an interest in the Chinese tourist market. However, due to the large volumes of data generated, new methods of analysis are required to examine the posts on Sina Weibo.

\section{Visual analytics and social media}

Visual analytics are methods for processing and synthesizing very large and complex data sets and information to make them transparent for analytic discourse (Keim et al., 2008). Visual analytics combine automated analysis techniques with interactive visualizations to aid effective understanding, reasoning and decision-making (Keim et al., 2008). Examples of past research are studies investigating tweet trending in a crisis (Kumar, Barbier, Abbasi, $\&$ Liu, 2011), and exploring the spatial and temporal dynamics of thunderstorms (Andrienko et al., 2010).

Only recently have tourism researchers begun to use visual analytic approaches to analyse and present their data, such as the use of word frequency in investigating the trend of tourism scholarship (Hunt, Gao, \& Xue, 2014), and the interactive visualization of hotel customer feedback from trip advisor (Wu et al., 2010). As Sina Weibo contains a vast amount of data that are difficult to analyse using common research methods, a visual analytic approach is required to aid effective understanding. Thus, this study seeks to examine the social media posts of Chinese Sina Weibo users in response to tourism news using a visual analytic approach.

\section{Methodology}

The first stage in examining the social media posts of Chinese Sina Weibo users is to narrow the focus of data collection. The researchers reviewed a number of leading Chinese news agencies' Sina Weibo accounts based on the agencies' number of followers and their authority (whether it is a Sina Weibo verified account). The latter is an indicator of Chinese public's confidence in the accountability of the postings (Gao, Abel, Houben, \& Yu, 2012). Eventually, CCTV News was selected. It is government-led, verified by Sina Weibo and its news is frequently reposted (re-tweeted) by its followers (22 million). To collect posts, we used the Sina Weibo search function to crawl CCTV News for common-related tourism posts by looking for related hashtags.

The method for tagging posts on Sina Weibo relies on the poster to prefix a term with the \# symbol resulting in a hashtag (\#tourist visa). The selection of particular postings (tourist visa news) was based on the times of the messages being reposted and the number of times people clicked 'like', as these numbers reflect the readership of a particular posting (Gao et al., 2012). That is, we selected the tourist visa posts that were reposted more than 1000 times. Due to the space restrictions of the research note, we only provide a representative sample of four of the most popular postings and a comparison between each of them. These four news items were about a simplified visa process for Chinese tourists visiting South Korea; fee waiver to Thailand for mainland Chinese and Taiwan passport holders; limitation of Chinese tourists to 5000 per day to Taiwan; and reduction of the visa 
Table 1. Four tourist visa news posts by CCTV.

\begin{tabular}{llc}
\hline & CCTV news post & $\begin{array}{c}\text { Number of } \\
\text { reposts }\end{array}$ \\
\hline Thailand & $\begin{array}{c}\text { Starting from August, the visa fee of Thailand tourist visa will be } \\
\text { waived for Mainland Chinese and Taiwan passport holders ... }\end{array}$ & 3393 \\
$\begin{array}{l}\text { South } \\
\text { Korea }\end{array}$ & $\begin{array}{c}\text { Starting from 2015, the visa process for Chinese tourists to South } \\
\text { Korea will be simplified and potentially waived .... }\end{array}$ & 5466 \\
Taiwan & $\begin{array}{c}\text { Starting from next year, the Taiwan government will limit Mainland } \\
\text { tourists to 5000 per day .... }\end{array}$ & 1332 \\
UK & $\begin{array}{c}\text { Starting from August, it only takes 24 hours for Chinese to get a } \\
\text { tourist visa to the UK ... }\end{array}$ & 2050 \\
In total & $\quad$ & 12,241 \\
\hline
\end{tabular}

processing time to 24 hours for Chinese visitors going to the UK (Table 1). In total, 12,241 reposts were analysed.

Figure 1 demonstrates the steps undertaken using a visual analytic approach. The first step as demonstrated earlier, was to select relevant Sina Weibo content and then prepare the unstructured data into structured data using a data mining algorithm and interactive visual tools. After several interactions with visual analytic tools, such as, GIS mapping toolcartodb, data were mapped using the open source visualization tool developed by the Visual Analytics Group at Peking University in China (http://vis.pku.edu.cn/weibova/).

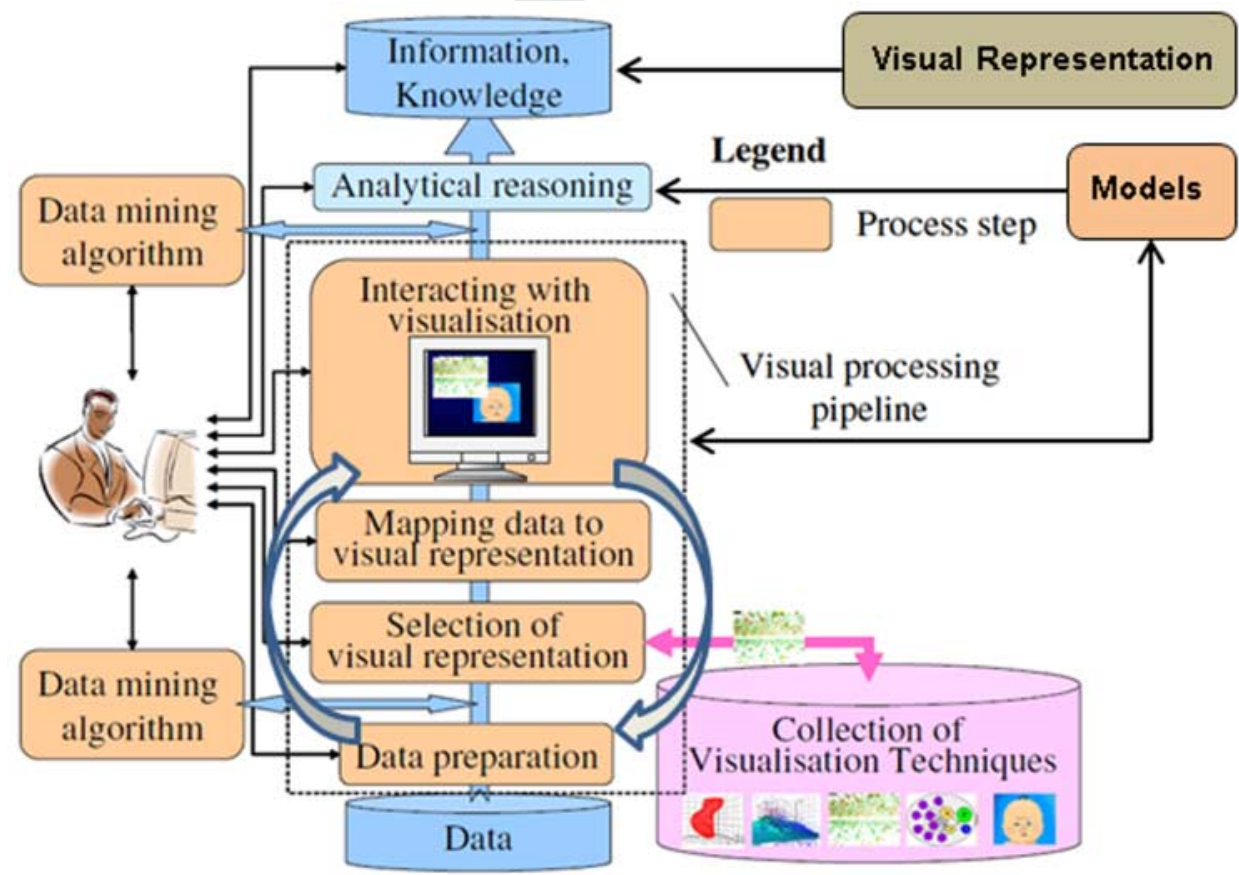

Figure 1. Visual analytics process (adopted from Simoff, Bohlen, \& Mazeika, 2008 and Keim et al., 2008).

Note: Darker colour represents a higher number of reposts. 
This software is free of charge for the Chinese public to analyse Sina Weibo data and is gaining wide popularity in China. More importantly, it offers an accurate and reliable visual presentation (Han \& Li, 2014).

The data preparation process is not a single step but an interactive process between human perception and computers (Keim et al., 2008) in which the data are structured, through iterative input into a model (e.g. statistical) for estimated results. In this scenario, the data are examined for relationships and patterns through the visual presentations combined with different models to better understand the data and subsequently generate insights, such as the readership of the tourist visa news. Finally, the knowledge is presented with interactive graphs and effective narration. It should be noted that visual analytics is more than just visualization as it enables the user to enter into a reflective loop whereby data are interactively manipulated to help gain both an understanding of, and the representation of, the data (Keim et al., 2008). It is an integrated approach to decision-making combining visualization, human factors, and data analysis as demonstrated in Figure 1.

\section{A brief discussion of present analysis}

Figure 2 presents the geo-visual analysis of Chinese consumers' response to the four visa news posts. The darker the colour, the higher the number of reposts generated by users in a province. The geo-visual presentation offers an instant understanding of the tourist interest regions in China and how consumers from various geographical regions reacted to different tourism destinations' tourist visa news. Overall, the highest reposts of the tourist visa news occurred in the relatively developed regions of China, including Beijing, Guangdong Province, Sichuan Province, Zhejiang Province, and Jiangsu Province. However, the visual analysis also shows that the news posting regarding the limitation of Chinese visitors to Taiwan raised interests across a number of Provinces in China, including Shandong, Sichuan, Hubei, Henan, Liaoniing, Inner Mongolia, Gansu, and Shaaanxi.

Figures 3 and 4 present the number of posts, posts by gender (orange - female; blue male), and the time duration of the reposts. As indicated by the geographical spread, the tourist visa news concerning South Korean tourist visa policy change received the largest number of re-postings (5466) (Table 1). This may indicate that Chinese consumers were excited by the prospect of less costly and simplified entry requirements into Korea. Figures 3 and 4 indicate that Chinese females may have a greater enthusiasm for outbound travel than males. This is consistent with recent industry reports which show that the number of Chinese females travelling outside China has grown rapidly and they have
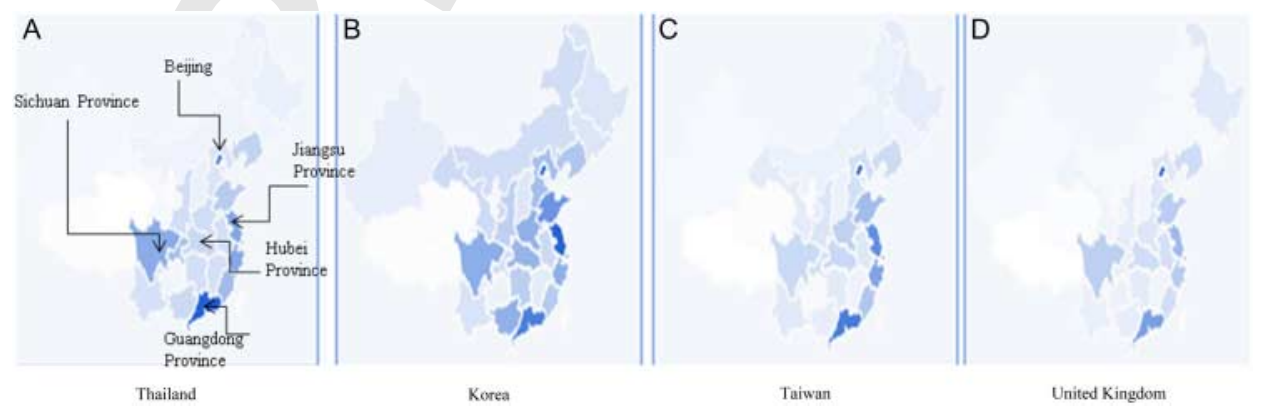

Figure 2. Province distribution. A, Thailand; B, Korea; C, Taiwan; D, UK.

Note: Darker colour represents a higher number of reposts. 
185

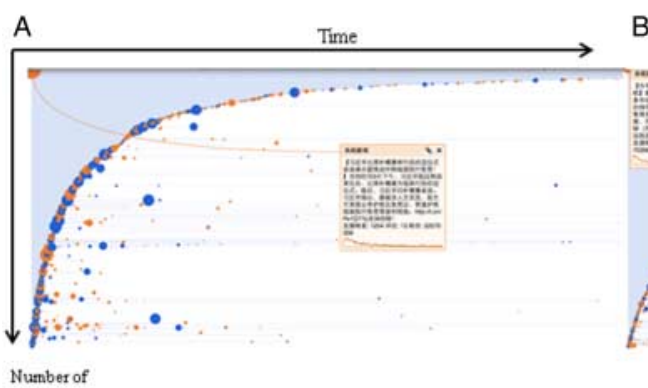

B

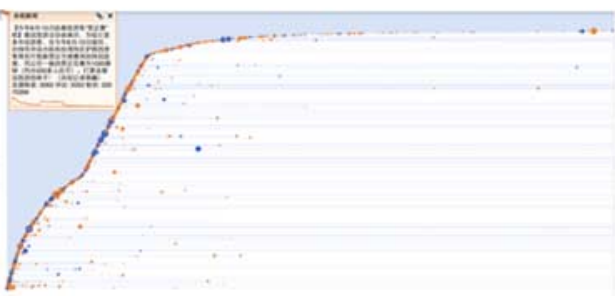

Number of

re-posting

Juty 4, 2014, 16:20

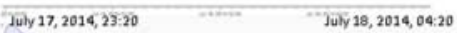

C Korea D

Thailand
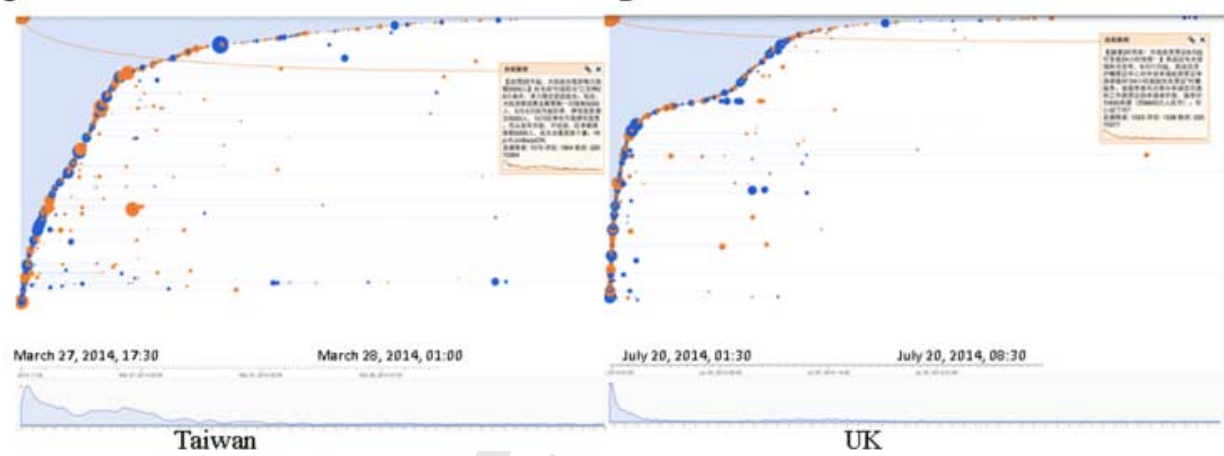

July $20,2014,01: 30$ July 20, 2014, 08:30

Figure 3. Time duration and number of re-posting.

Note: Orange circle - female, blue circle - male.

210

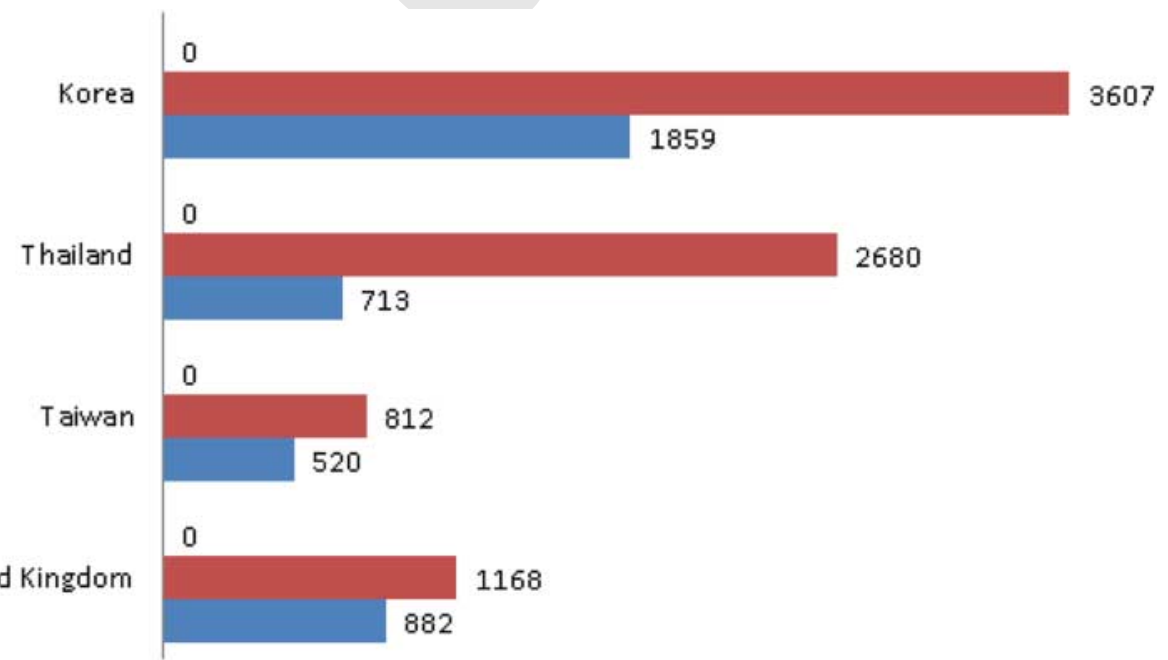

- Unknown afemale Male

Figure 4. Gender distribution. 

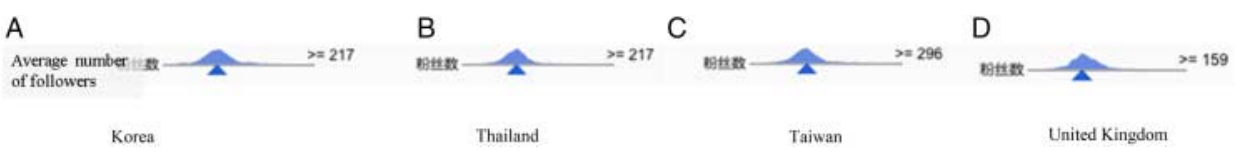

Figure 5. Average number of followers who follow people who reposted the tourist visa news.

become the primary target market for many travel businesses (Sohu Travel, 2014). The time duration in Figure 3 shows that the average life span of the four tourist visa news posts is 6.5 hours. This time period presents an opportunity for DMOs to engage with their Sina Weibo consumers by providing tourism services and products that are relevant to the news postings.

The size of the circles in Figure 3 is an indicator of the number of people who follow people who reposted the tourist visa news. The bigger the circle is, the larger the number of followers of a particular user who has reposted. Notably, the reposts generated far more impact than the users who post it, as re-posting means sending out the travel news a stage further to their followers. It shows the influence of particular travel visa news and its impact in reaching a large number of potential travellers. Combining the average numbers of followers (Figure 5) and the total reposting number (Table 1) (average number of followers * total number of reposts), we calculated the readership of the tourist visa news by using the formula $-Y$ (readership) $=a$ (average number of followers) ${ }^{*} b$ (number of reposts), we found that tourist visa news reposting on South Korea $(1,186,122)$ reached the largest amount of users, while the UK received the least $(325,950)$.

A word frequency analysis was conducted on the reposts to understand Chinese consumers' sentiments towards the tourist visa news. The findings indicate that Chinese consumers were happy with the visa policy change for Thailand and Korea (e.g. support and applause), were surprised with England (e.g. surprised and what), and were unhappy with Taiwan (e.g. limit and how come), for limiting the number of Chinese mainland visitors. By combing the analysis from Figures 2 and 5, those most interested in the simplified visa process for Korea were from Guangdong Province, Jiangsu Province, and Beijing. Consumers from Beijing and Guangdong Province were most interested in the simplified visa process for the UK, while consumers from Guangdong Province, Beijing and Jiangsu Province demonstrated highest negative sentiments regarding the daily limitation on the number of Mainland Chinese tourists to Taiwan (Figure 6).

These findings can offer insights for governments and destination managers. There is an opportunity for agencies to capitalize on the positive sentiments towards their visa policy changes to encourage visitation to their countries. This could be through subsequent posts on travel specials, tour packages, and business-related opportunities. Alternatively,

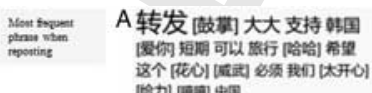
Irvel, Haha, Hope, This,

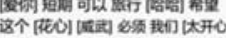

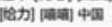

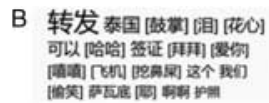

Applases, Bisties Support, Korea, Loveyou Shot, Olay, Poot Happy, Gell, Xixi, Cling

Korea

Visa proeess simplified for Chinese tourists visiting South Korea Playboy, Olay, Haha Visa, S you, Love you, Xm, Airplane Picking nose, This, We, L sugh,
Sowadila, Yeah, Hinhs Passport

Thailand

Fee waiver for Mainland Chinese and Taiwan passport holders
C 转发茶叶雷台灣大陆 旅游 (控鼻星) 甈制我们什么

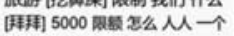
越方

Tea eges, Taiwan, Mainland, Trave Picking nose, Limit, We, What? See you, 3000 , Limit number, Hion, Everyone, Ose plact, Net:
This? This Year, Hehe

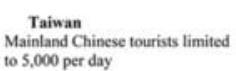

转发签证 6600 [臤科] 英国

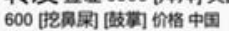

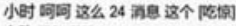
O何

Visa, 6600, See you, UK, 600, Picking nose, Applanes, Price, Thisis, Surprised, Touctind, Senvice, Thas, Surprised, Touched, Service.
Pound

United Kingdom Visa process reduced to 24

Figure 6. Most frequent phrase when reposting. 
there are opportunities for agencies to manage negative sentiment arising from these reposts by providing additional travel services and products which can assist consumers in navigating and planning their future travel.

\section{Conclusion}

Visual analytic approaches are gaining wide popularity but are not frequently used in the tourism literature so far. Our approach differs from traditional methods of social media research in tourism that has primarily relied on manual processing of text, sentiment, and image (Mkono, 2012; Wu \& Pearce, 2013). Additionally, research analysis has focused on visualization as a representational tool rather than an analytical process (Rakic \& Chambers, 2012; Stepchenkova \& Zhan, 2013). Here visual analytics as demonstrated in Figure 1 focuses on the human perception and computer interaction by utilizing their respective distinct capabilities for the most effective results. The contribution of the visual analytics approach is to assist researchers to address challenges presented by large volumes of unstructured data. In doing so, this approach provides researchers with an alternative method to effectively manage, analyse, visualize, and present their data. Thus, the extension of this approach to broader tourism methodological literature is relevant to other contexts, which involve large amounts of unstructured data.

We demonstrated the effectiveness of this approach by using the case study of Sina Weibo content and discovered potential tourist interest regions, the life span of travel news and tourists' attitudes towards travel policy changes; that may not otherwise have been analysed and presented. In particular, this study shows that a visual analytic approach can help researchers better understand, transform, and present data into actionable insights. The approach also has practical applications in that the geo-visualization of reposting regions enable DMOs to make real-time decisions which can assist them to effectively predict future consumer behaviours and capitalize on marketing initiatives.

More importantly, China, as a world tourist generating market, is seldom investigated through the lens of self-established social media - Sina Weibo, which differs substantially from its Western counterparts. This article innovates by introducing the Chinese social media data to Western researchers, bridging in the East and West understanding of social media landscapes. Thus, this study is an early attempt to shed light on two under researched areas - social media in China and visual analytics in tourism.

However, further research which combines the visual analytic approach with other traditional methods can generate additional insights from current tourism-related social media phenomena. Drawing inferences and conclusions from social media data still incur traditional social research problems (i.e. user bias and limited contextual knowledge). As such, the efforts of collaborative, multidisciplinary teams (i.e. information technology, management, economics, computational linguistics, engineering, and sociology) can better address the data mining challenges and opportunities presented by large volumes of social media data.

\section{Disclosure statement}

No potential conflict of interest was reported by the authors.

\section{References}

Andrienko, G., Andrienko, N., Demsar, U., Dransch, D., Dykes, J., Fabrikant, S. I., ... Tominski, C. 
Gao, Q., Abel, F., Houben, G.-J., \& Yu, Y. (2012). A comparative study of users' microblogging behavior on Sina Weibo and Twitter. In User modeling, adaptation, and personalization (pp. 88-101). Springer.

Han, Y., \& Li, X. (2014). How to examine the impact of Weibo. Shanghai Journal Review (7), 60-64.

Hays, S., Page, S. J., \& Buhalis, D. (2013). Social media as a destination marketing tool: Its use by national tourism organisations. Current Issues in Tourism, 16(3), 211-239. doi:10.1080/ 13683500.2012 .662215

Hudson, S., \& Thal, K. (2013). The impact of social media on the consumer decision process: Implications for tourism marketing. Journal of Travel \& Tourism Marketing, 30(1-2), 156-160. doi:10.1080/10548408.2013.751276

Hunt, C. A., Gao, J., \& Xue, L. (2014). A visual analysis of trends in the titles and keywords of topranked tourism journals. Current Issues in Tourism, 1-7. doi:10.1080/13683500.2014.900000

Keim, D., Andrienko, G., Fekete, J., Gorg, C., Kohlhammer, J., et al. (2008). Visual analytics: Definition, process and challenges. In A. Kerren, J. T. Stasko, J.-D. Fekete, \& C. North (Eds.), Information visualization - Human-centered issues and perspectives (pp. 154-175). Springer, LNCS. http://hal-lirmm.ccsd.cnrs.fr/lirmm-00272779/document

Kumar, S., Barbier, G., Abbasi, M. A., \& Liu, H. (2011). TweetTracker: An analysis tool for humanitarian and disaster relief. Paper presented at the Icwsm.

Kurashima, T., Iwata, T., Irie, G., \& Fujimura, K. (2010). Travel route recommendation using geotags in photo sharing sites. Paper presented at the proceedings of the 19th ACM international conference on information and knowledge management.

Mairin. (2014, September 16). Travel without visa: Go as you wish, ChinaLuxus. Retrieved from http://travel.chinaluxus.com/Vac/20140916/297000.html

Mkono, M. (2012). A netnographic examination of constructive authenticity in Victoria Falls tourist (restaurant) experiences. International Journal of Hospitality Management, 31(2), 387-394. doi:10.1016/j.ijhm.2011.06.013

Nelson, C. (2013, July 29). Destinations target Chinese tourists on Weibo, China Business Review. Retrieved from http://www.chinabusinessreview.com/destinations-target-chinese-tourists-onweibo/

Rakic, T., \& Chambers, D. (Eds.). (2012). An introduction to visual research methods in tourism. New York, NY: Routledge.

Ramzy, A. (2011, February 21). Wired up, Time Magazine. Retrieved from http://www.time.com/ time/magazine/article/0,9171,2048171,00.html

Ren, D., Zhang, X., Wang, Z., Li, J., \& Yuan, X. (2014). WeiboEvents: A crowd sourcing Weibo visual analytic system. Paper presented at the IEEE Pacific Visualization Symposium (PacificVis).

Simoff, S., Böhlen, M. H., \& Mazeika, A. (2008). Visual data mining: Theory, techniques and tools for visual analytics. New York, NY: Springer.

Sohu Travel. (2014). The 2014 Spring report of Chinese outbound tourists' characteristic. Retrieved December 16, 2014, from http://ravel.sohu.com/s2014/tushuo01/

Stepchenkova, S., \& Zhan, F. (2013). Visual destination images of Peru: Comparative content analysis of DMO and user-generated photography. Tourism Management, 36, 590-601. Doi:10.1016/j. tourman.2012.08.006

Sullivan, J. (2012). A tale of two microblogs in China. Media, Culture \& Society, 34(6), 773-783. Doi: $10.1177 / 0163443712448951$

Wu, M., \& Pearce, P. L. (2013). Appraising netnography: Towards insights about new markets in the digital tourist era. Current Issues in Tourism (ahead-of-print), 1-12.

Wu, Y., Wei, F., Liu, S., Au, N., Cui, W., Zhou, H., \& Qu, H. (2010). OpinionSeer: Interactive visualization of hotel customer feedback. IEEE Transactions on Visualization and Computer Graphics, 16(6), 1109-1118.

Xinhua News. (2013, February 21). Weibo's registered users exceeded 500 Million. Retrieved from http://news.xinhuanet.com/tech/2013-02/21/c_124369171.htm

Ye, Q., Law, R., Gu, B., \& Chen, W. (2011). The influence of user-generated content on traveler behavior: An empirical investigation on the effects of e-word-of-mouth to hotel online bookings. Computers in Human Behavior, 27(2), 634-639. doi:10.1016/j.chb.2010.04.014 